\title{
MEMÓRIAS
}

\section{DE TRABALHADORES RURAIS NA CIDADE}

\section{Charles D'Almeida Santana*}

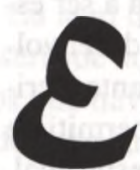

ntre os anos de 1960 e 1980 o

cotidiano em Salvador modifi-

cava-se por força da presença de

lavradores expulsos do campo

baiano e por conta de diversas facetas do processo de industrialização pelo qual passava. Simultaneamente, a região dos municípios de Conceição do Almeida e Santo Antonio de Jesus, no Recôncavo Baiano, experimentava uma profunda transformação em seus modos de vida e de luta no campo. A concentração de terras, a extinção das roças de café e de fumo, o fechamento de engenhos de açúcar e a ampliação da criação de gado, processos históricos articulados entre si, empurravam os trabalhadores rurais para cidades próximas, outras regiões e estados brasileiros. Nessas circunstâncias, obviamente, a migração foi a alternativa para uma expressiva parcela dos agricultores da região, especialmente para as novas gerações que se viram sem perspectiva de encontrar terras para o trabalho.

A cidade de Salvador foi um dos principais destinos dessa onda migratória. Esta opção pela capital deve-se à ampliação de oferta de empregos, em toda sua Região Metropolitana, e à proximidade entre as duas regiões. Assim, os trabalhadores dos municípios considerados participaram, por variados caminhos, no processo cultural, no fervilhar da vida tanto rural quanto urbana da Bahia. Neste texto, nossos olhares voltam-se a alguns impasses que surgem quando buscamos interpretar, nas dinâmicas do dia-a-dia na capital baiana, a participação de trabalhadores oriundos daquela determinada região rural do Estado.

\section{LEMBRANÇAS DO CAMPO NA CIDADE}

Vale dizer que, durante o período, os múltiplos limites e pressões da cidade sobre os migrantes e os diferentes impactos desses migrantes na construção e reconstrução de espaços urbanos, em Salvador, são incorporados no universo do cotidiano citadino. Nesse processo, destaca-se a importância de memórias de trabalhadores do campo na cidade, lembranças que apontam continuidades e nítidos laços entre o urbano e o rural objetivados nos "lugares da memória" qualitativamente construídos e reconstruídos por migrantes.

A qualidade aqui pensada trata do cruzamento de inúmeras experiências e vivências do homem do campo em um mundo urbano. Suas representações sociais experimentaram velozes e efêmeras transformações em face das circunstâncias cambiantes, quer seja no ponto de partida, quer seja no ponto de chegada. As tradições, enquanto conteúdo da memória, são explicitamente selecionadas à proporção em que os trabalhadores relacionavam-se com uma realidade absolutamente nova, atraente e objeto do "fazer futuro" para os ex-lavradores.

Sabe-se que as ações humanas, no dinamismo urbano, estão envolvidas por uma complexa gama de instituições, práticas e representações inexistentes na realidade campesina. "Há mais em jogo, e mais a parder, na cidade; ali o equilíbrio é mais precário, e o perigo, maior; os breves momentos de descanso são mais difíceis de perceber; o sucesso e o fracasso manifes- 
tam-se sob formas novas e mais problemáticas" (Williams, 1990: 303).

Nessa conjuntura, os trabalhadores rurais que chegaram à capital baiana, desambientados, conseguiram manter relações semelhantes àquelas tradicionais no campo, especialmente no que se refere a práticas de solidariedade. Por exemplo, a de compadrio que, para além da política de coronéis, apresentava-se no interior do Estado em diversas formas: a de batismo, a de crisma, a de casamento, a de fogueira e a de parteira.

A busca de suas identidades citadinas, marcada por tropeços e acertos, significava uma convivência com compreensões mistas do urbano como um distante reino da luxúria e o lugar onde poderiam conquistar direito ao trabalho. Temor e admiração foram, provavelmente, as primeiras sensações na vida urbana; ceder às luzes ou padecer no caos; sobreviver à "saudade das festas de São João, das festas da fogueira", ou, conforme as recordações de Antonio Oliveira', morrer como "um peixe fora d'água", junto a um "monte de gente supersofisticada, no Elevador Lacerda, que elevador era esse? E o medo daquele negócio quebrar e ficar preso. E como sair?"

\section{RECORDAÇÕES E RESISTÊNCIAS}

Enfim, situações semelhantes encontradas em estórias preservadas/modificadas na tradição oral dos trabalhadores, podendo ser compreendidas a partir de diversas versões. Entre variadas possibilidades de leitura, uma diz respeito a visões da cidade elaboradas no mundo agrário brasileiro e a importantes dimensões da memória de lavradores ao chegarem em Salvador. $\mathrm{Na}$ literatura de Cordel, por exemplo, surpreendemos traços de rememorações de agricultores sobre o viver na cidade.

Nesse sentido, é significativo o conto intitulado "Juvenal e o Dragão". Nesta literatura oral, a vida ubana, genericamente denominada de reino, é vista controlada por uma fera assassina de belas jovens e lugar de mesquinharias e artimanhas praticadas por pessoas desprezíveis. Contudo, Juvenal, um lavrador que decidiu correr o mundo, migrar para a cidade, encontra o dragão e salva uma princesa, por extensão a população de toda a cidade, ma- tando-o com o auxílio de seus três cães. Termina feliz para sempre na condição de herói, de rei da cidade e adorado pela jovem, com quem se casa. Toda narrativa tematiza a morte na cidade, a desordem urbana, e a alternativa da paz social ser restabelecida por um simples, corajoso e arrojado agricultor. Portanto, o trabalhador rural aparece como aquele que pode vencer na cidade.

Mas, enquanto a implacável realidade, percebida como se fosse um "dragão", tentava submetê-los por inteiro, eles forjaram um cotidiano matizado por um tipo específico de resistência. Em meio a incertezas acerca da alternativa de vida a ser escolhida, sua presença na cidade desenvolveu-se carregada de uma incessante e criativa procura de atividades que permitisse resistir à própria morte física e espiritual. Tal perspectiva mostra-se notadamente no que se refere às "festas da fogueira", no mês de junho.

Nos dias próximos a São João e São Pedro, os espaços urbanos eram redecorados como pontos de venda de milho, amendoim, toros de árvores. Algumas ruas, asfaltadas ou não, recebiam o implante de pés de banana ao lado da fogueira a ser queimada. As labaredas iluminavam as casas daqueles que, por não conseguirem viajar para o interior, bebiam licor ao mesmo tempo em que relembravam as "festas da fogueira" na roça. Outros divertiam-se em eventos organizados pelo poder público que, se de um lado aproveitava, de outro rendia-se às pressões surdas dos migrantes em Salvador.

\section{MEMÓRIAS DO CAMPO E DA CIDADE}

Em outro sentido, os lavradores vivenciaram, na cidade de Salvador, o moderno e $o$ antigo também em outras práticas sociais enquanto resistência aos traumas da exploração, uma fuga da miserabilidade, ao fundirem costumes, hábitos e valores do seu mundo rural de origem a outros citadinos. Um dos melhores destaques é o da religiosidade: o misticismo interiorano, pouco ortodoxo, mesclou-se com o de Salvador, criando novas práticas religiosas.

Os migrantes procuravam indistintamente o catolicismo popular e o oficial, a rezadeira com galhos de plantas, o jogador de búzios, a cartomante, a umbanda, o candomblé, as rezas ou ladainhas em latim "aportuguesado" (um tipo de culto feito em frente a um singular altar de divindade cristã, podendo ser seguida de festa com atabaques, caruru, incorporação de caboclo, cacachaça, samba-de-roda, etc.). As religiões de origem africana, anteriormente reprimidas pela polícia na capital, ampliaram-se. Ainda na condição de absolutamente conservadoras e confinadas em seus próprios terreiros, onde permitia-se a frequência somente a iniciados, elas são invadidas pelos migrantes, "renovandose". Dessa perspectiva, e em uma sintonia tensa do campo com a cidade, os terreiros de candomblé teriam cedido ao peso de extrabalhadores rurais.

Assim, à medida em que os migrantes forjavam paisagens urbanas impregnadas de costumes, hábitos e valores agrários, seletivamente incorporados nas práticas sociais, tendia a reduzir a sensação de estranhamento quanto ao mundo urbano, de perceber-se perdido em meio à multidão como uma perda da própria identidade. Frente às dificuldades encontradas ao tentar sobreviver em uma realidade histórico-cultural desconhecida, os trabalhadores "transportaram" tradições do campo baiano e, de algum modo, reforçaram costumes e hábitos proporcionando a criação de um universo repleto de inúmeras maneiras de viver. O novo cotidiano realizase intensamente nas ruas, nos "finais de linha" de ônibus, na praia durante todos os dias do ano.

A população de Salvador tem o seu diaa-dia adornado pelos versos dos repentistas, dos cantores de chula e samba-de-roda nas praças, no transporte coletivo e nas casas, no Mercado Modelo, no Pelourinho. São diversas cidades. E uma "outra Salvador - que é a mesma - também existe. Salvador do trabalho diário e estafante, do subemprego, dos momentos vários de auge econômico e das prolongadas crises de estagnação, da produção de riquezas e, sobretudo, da pobreza cotidiana e dificil". (Faria, 1980: 23).

Nesse contexto, em que variados condicionantes pressionam no sentido da criação de novas modalidades de relações, uma diferente forma de viver o dia-a-dia 
mostra-se na veloz dinâmica urbana dos trabalhadores, nos espaços da cidade, em suas práticas diárias. Vivências que marcaram profundamente a construção de sua identidade e o seu envolvimento na invenção de modos de vida urbanos: a manutenção de relações objetivas com o interior baiano.

Já nas utopias, projetos e representações quanto à futura vida em Salvador, notamos dimensões indicativas do retorno ao campo. Ao nível das intenções, após conseguirem emprego na cidade, eles voltariam para a próxima festa de São João, para o Natal ou casamento de alguém; para buscar seus parentes ou comprar um sítio. Realizando plenamente ou não seus projetos, eles encontraram alternativas eficazes para manter vínculos com o lugar de origem: são redes de encontros cujo principal objetivo é a troca de notícias, recados, cartas e recordações.

Dada à proximidade entre a capital e algumas áreas do interior, as viagens e as comunicações ocorreram com uma fequência suficiente a lhes permitir uma forte sensação de continuidade de pertencimento ao mundo agrário, articulando dramaticamente o passado e o presente do campo e da cidade. Um reforço à memória que modifica sua interação com a vida citadina, assim como a própria memória.

Concomitantemente, a vida nas áreas rurais da Bahia passava por mudanças sintetizadas na formação de grandes propriedades, no extermínio de quintais de café, no desaparecimento de vilas camponesas, na generalização da pecuária bovina, no desemprego e na expulsão de trabalhadores rurais das roças.

Processos diferenciados no campo e na cidade. Mas todos articulados historicamente em um único movimento em que subordinava a produção rural ao núcleo industrial do Estado. No âmago de tal movimento, os migrantes refaziam espaços e modos de vida na cidade de Salvador, num processo de redefinição dos sujeitos e dos modos de ser da própria cidade, criando uma "cidade ilegal", "clandestina", dentro da "cidade legal”, "cidadã”, implantada nos anos da ditadura militar no Brasil.

É de se pensar a importância do viver espaços e tempos diferentes e divergentes, no intuito de analisar o cotidiano dos tra- balhadores migrantes e suas identidades históricas. Em um mesmo instante, eles viveram maremotos no campo e na cidade: múltiplas pressões vividas pelas mesmas pessoas, no seio de um único movimento histórico-cultural. São cobranças da capacidade de lidar com realidades do urbano e do rural que acarretam apropriações necessárias repletas de antagonismos e conflitos.

Tal capacidade de convivência pode ser percebida nas experiências dos migrantes quanto à realidade vivida e nas lutas travadas na cidade. Suas representações sociais participam efetivamente na elaboração da história consubstanciada em valores, hábitos, costumes saturados por elementos de suas memórias do mundo rural, lembranças que abrem possibilidades de mergulhar no "tempo contido no instante em que a luz da estrela cadente cintila para uma pessoa". (Benjamin, 1989: 129)

\section{SALVADOR DE MIGRANTES}

A memória dos migrantes contribuiu decididamente no processo cultural urbano de Salvador. Estudar a presença de extrabalhadores rurais, na capital baiana, significa considerar uma específica transplantação de hábitos, valores, tradições e saberes camponeses na construção da paisagem social da cidade, cujo cotidiano coexiste com uma ruptura no seio das relações em todo Estado. Imediatamente à sua chegada, chocados com o mar e o porto, a multidão e as vitrines, as luzes, suas representações a respeito da cidade sofreram alternâncias.

Antes, a "cidade da Bahia" era o lugar da luxúria, da exuberância desmedida, onde os doutores se formavam. Agora, é o lugar de "fazer um futuro", onde ex-lavradores agem no dia-a-dia em circunstâncias mais complexas, reinventando a vida e "instituindo espaços novos de convivência em que as experiências sociais desses sujeitos se confrontam no desenho da nova cidade" (Cruz, 1994: 82), mas sem permitir o aniquilamento de todas as dimensões de suas identidades anteriores.

Olhar Salvador do ângulo do trabalhador oriundo do campo baiano significa penetrar no "Canto do Povo de um Lugar". É repensar a política modernista da técnica infalível, contraposta a um fazer-se su- jeito histórico resistente ao anonimato e à automação urbano-industriais. Uma vez recém-imersos em um mundo de heterogeneidades e de pressões daquela realidade urbana sobre suas vidas, suas estratégias de sobrevivência passaram a marcar a cidade: um outro lugar da tradição, da história e da memória.

* Charles d'Almeida Santana é doutorando em história da PUC-SP e Prof. da Universidade Estadual de Feira de Santana e da Universidade do Estado da Bahia, campus de Santo Antonio de Jesus.

\section{NOTA}

1- Antonio Oliveira é ex-trabalhador rural do Recôncavo e reside em Salvador desde 1967, aproximadamente. Este depoimento data de janeiro de 1997.

\section{BENJAMIN, Walter}

\section{BIBLIOGRAFIA}

(1989) Charles Baudelaire: um lírico no auge do capitalismo. São Paulo, Brasiliense. Obras Escolhidas, v.3.

CERTEAU, Michel de

(1994) A Invenção do Cotidiano: Artes de Fazer. Petrópolis, Vozes.

CRUZ, Heloisa de Faria

(1994) Na cidade, sobre a cidade; cultura letrada, periodismo e vida urbana. São Paulo1890/1915. Tese de Doutorado, USP, Dpto. de História.

FARIA, Vilmar E.

(1980) "Divisão Inter-Regional do Trabalho e Pobreza Urbana: o caso de Salvador". In: Guaracy Adeodato de Souza (org.). Bahia de Todos os Pobres. Petrópolis, Vozes/CEBRAP.

FERNANDES, Ana (org.)

(1990) Anais da $3^{a}$ Semana de Urbanismo. Salvador.

RONCAYOLO, Marcel

(1986) Cidade. In Região. Enciclopédia Einaudi. Lisboa, Imprensa nacional - Casa da Moeda, vol.8.

OLIVEIRA, Francisco de (1987) O Elo Perdido - classe e identidade de classe. São Paulo, Brasiliense.

SANTANA, Charles d'Almeida

(1998) Trabalhadores Rurais do Recôncavo Baiano: memórias e linguagens. In: Projeto História, Revista do Programa de Estudos PósGraduados em História e do Dpto. de História da PUC/SP, no 16, fev/98, pp. 193-209.

SOUZA, Angela Maria Gordilho

(1990) Invasões e Intervenções Políticas: uma política de atribuição espacial em Salvador, 1946-1989. Rio de Janeiro, Instituto de Planejamento Urbano e Regional-UFRJ, mimeo.

WILLIAMS, Raymond

(1979) Marxismo e Literatura. Rio de Janeiro Zahar.

WILLIAMS, Raymond

(1990) O Campo e a Cidade na História e na Literatura. São Paulo, Cia de Letras. 